\title{
Use of geophysical methods in investigating PRBs employing non-conductive reactive materials
}

\author{
Y. S. Kim, J. J. Kim, G. H. Lee \& J. B. Park \\ School of Civil, Urban and Geosystem Engineering, \\ Seoul National University, Korea
}

\begin{abstract}
Resistivity survey and ground penetrating radar (GPR) were used for investigating a full-scale permeable reactive barrier (PRB) installed nearby abandoned mines of the Go-sung area, located on the south coast of the Korean peninsula. The aims of the testing program included evaluating the applicability of geophysical methods in: 1) locating PRB installations, 2) investigating the movement of groundwater through the PRB and 3) qualitatively identifying the extent of contaminant removal on the PRB. The results indicated that both resistivity and GPR surveys were applicable in giving exact locations of PRB installation based on given information on the reactive material properties, including particle size, composition and electrical characteristics. The resistivity survey was also successful in evaluating the movement of groundwater at different locations nearby the PRB installation. On this basis, results and discussion of the testing program provides evidence of the reliability of geophysical surveys to be used as in-destructive methods for investigating PRBs in operation.
\end{abstract}

Keywords: permeable reactive barriers, abandoned mines, heavy metals, resistivity survey, ground penetrating radar.

\section{Introduction}

Permeable reactive barrier (PRB) has gained wide acceptance as an effective technology to remediate a variety of contaminants present in groundwater. The technology has many advantages over traditional methods of remediation, in that it is passive and a large amount of contaminants can be treated in a cost-effective 
manner [6]. In Korea, several PRBs are known to have recently been installed nearby abandoned mines as a means of intercepting possible release of contaminants from mine tailing dumps. While the technology has proven to be an efficient approach to remediate a wide range of contaminants worldwide, a limited number of reports have been made to investigate the performance of PRBs after installation. In the long term, PRBs may experience reduction in efficiency of contaminant removal, reduction in permeability from build up of mineral precipitates, and build-up of microbial biomass [5, 6]. In addition, PRBs can be damaged or may not operate as designed if not properly managed during its years of operation after installation.

A full-scale permeable reactive barrier (PRB) installed nearby abandoned mines of the Go-sung area, located on the south coast of the Korean peninsula was the study site for performance monitoring. This research reports the results of geophysical surveys conducted prior to intensive groundwater and reactive material sampling. While more than $50 \%$ of full-scale PRB installations worldwide use granular iron as the reactive media [3], non-conductive reactive media such as steel slag and zeolite were employed at the study site. The aims of the testing program included evaluating the applicability of geophysical methods in: 1) locating PRB installations, 2) investigating the movement of groundwater through the PRB and 3) qualitatively identifying the extent of contaminant removal on the PRB.

The greatest advantage of using geophysical method is that it provides indestructive means of understanding the subsurface conditions nearby PRB installation. In addition, high resolution images can be obtained through rapid data acquisition. Without such prior investigation, efforts made in order to monitor PRBs involving drilling compliance wells may become laborious and cause costly damage. Interpretations made in this study were to aid in understanding the subsurface characteristics and selecting locations for groundwater and soil sampling.

\section{Site description}

The study site of PRB installation is located nearby an abandoned mine which was in operation during the early 1950 s to the mid 1960s. After the copper mine was abandoned, use of contaminated surface water for household and agricultural supply continued until there were doubts of possible outbreak of a number of diseases from heavy metal poisoning. The needs for taking restoration measures were recognized by the public more recently. The Mine Reclamation Corporation installed vertical walls around the mine tailing dump and a group of pile-type PRBs at an open end of the vertical walls in order to prevent any movement of contaminants out from the mine tailing dump.

A total of four non-conductive reactive materials were used in the pile-type PRB under study, which are zeolite, iron coated sand, steel slag and activated carbon. These reactive materials were selected for remediating groundwater contaminated from acid mine drainage, consisting heavy metals including cadmium and arsenic. Five rows of pile-type PRBs with a vertical length of $6 \mathrm{~m}$ 
and a diameter of $0.25 \mathrm{~m}$ were aligned in a zigzag pattern to create a group of pile-type PRBs with a total width of $2.25 \mathrm{~m}$. Reports made prior to installation revealed that the nearby soils and groundwater were primarily contaminated by copper and cadmium, respectively. In addition, mine tailing dump was estimated to contain approximately 1,000 kilograms of arsenic and 5,500 kilograms of copper. Although only 2 years have passed since its installation, the exact location of pile-type PRBs was questionable. This was primarily because the group of pile-type PRBs was installed at a privately owned property which made management difficult. Even with the aid of ground positioning system (GPS) and design data, locating the pile-type PRBs was challenging due to the limited level of precision.

\section{Description of geophysical survey}

Resistivity survey and ground penetrating radar (GPR) were used for investigating the study site. Prior to conducting geophysical surveys, GPS was employed to aid in marking exact locations of the grid lines. The GPR survey was conducted in an effort to locate the pile-type PRB installations. Therefore a total of 3 grid lines were directed perpendicular to the estimated direction of the PRB installation, as shown in figure 1. The survey was conducted using a $100 \mathrm{MHz}$ Pulse EKKO transmitter and receiver antennae pair. Although the depth of penetration may dependent on the dielectric properties of the underlying soil, it was considered to be sufficient since the pile-type PRBs were designed to be buried at a depth of 1 to $2 \mathrm{~m}$ from the surface.

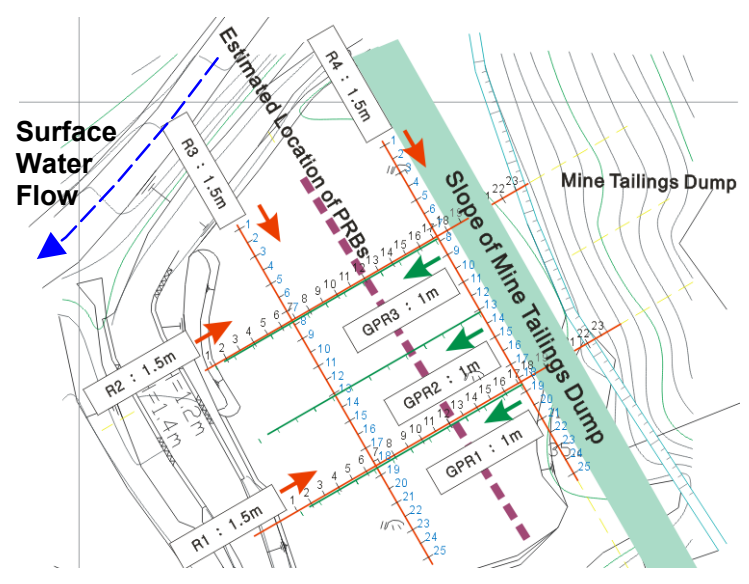

Figure 1: Schematic diagram showing grid lines of geophysical surveys conducted at the study site.

A total of 4 grid lines were selected for resistivity survey. Since the resistivity survey was conducted in an effort to investigate the subsurface conditions and movement of groundwater in addition to locating PRB installation and identifying the extent of contaminant removal, grid lines were directed both 
parallel and perpendicular to the pile-type PRBs (refer to figure 1). Wenner arrays were employed by placing electrodes $1.5 \mathrm{~m}$ apart, which gives a penetration depth of $7.5 \mathrm{~m}$ ( $\fallingdotseq 5$ times the electrode spacing). Since the surface of the study site contained a significant amount of large gravels and rocks, salt water was discharged in order to increase the contact resistance between the subsurface and stainless steel electrodes.

\section{Results}

\subsection{GPR survey}

Results of the GPR images obtained from lines perpendicular to the pile-type PRBs are shown in figure 2. Since $100 \mathrm{MHz}$ antennas were used, the maximum penetration of the radar signals was approximately $3 \mathrm{~m}$, and images obtained at deeper levels were considered to be dominated by noise (thus considered unreliable). Generally, interpretation of GPR results is focused on searching for anomalies such as hyperbolic reflections, irregularities in largely uniform reflection patterns, and changes in frequency of the signals [4]. Hyperbolic reflections are caused by point reflectors in the ground, while irregularities in largely uniform reflection patterns are usually caused by disturbances to the natural sedimentation of soils as a result of construction. Changes in the frequency of radar signals are dominated by the dielectric properties of the subsurface medium, which is primarily effected by the volumetric moisture content.

As shown by the dotted circles of figure 2, the GPR image contains significant number of anomalies, which are predominantly irregularities in largely uniform reflection patterns. These anomalies are believed to be caused by disturbances in soil medium from the construction work performed to remediate and immobilize heavy metal contaminants (including pile-type PRBs and vertical walls surrounding the mine tailings dump). Note that natural sedimentation can not be anticipated at the study site, since original soil was excavated and covered by nearby soils prior to installation of pile-type PRBs. A clear hyperbolic reflection was observed at a low depth in GPR3 image which was later visually confirmed to be a buried steel pipe through excavation. Such hyperbolic pattern is created as the reflected signal appears to rise towards the surface as the transducer approaches and passes over it.

Anomalies seen at (horizontal) locations corresponding to 11-15 m of GPR2 image and 10-14 m of GPR1 image are believed to be pile-type PRBs. It appears at a depth between 1.5 to $2 \mathrm{~m}$. Although the anomalies do not necessarily bear resemblance to the shape or size of the target causing the reflected signal, piletype PRBs were found to create large trapezoidal shaped anomalies. Differences in the particle size, particle size distribution, and water content of reactive materials from surrounding soils may be the principal reasons which cause such anomalies. However, pile-type PRBs were not observed in the GPR3 image. Such results suggest possible damage in pile-type PRBs at locations corresponding to the GPR3 line. 

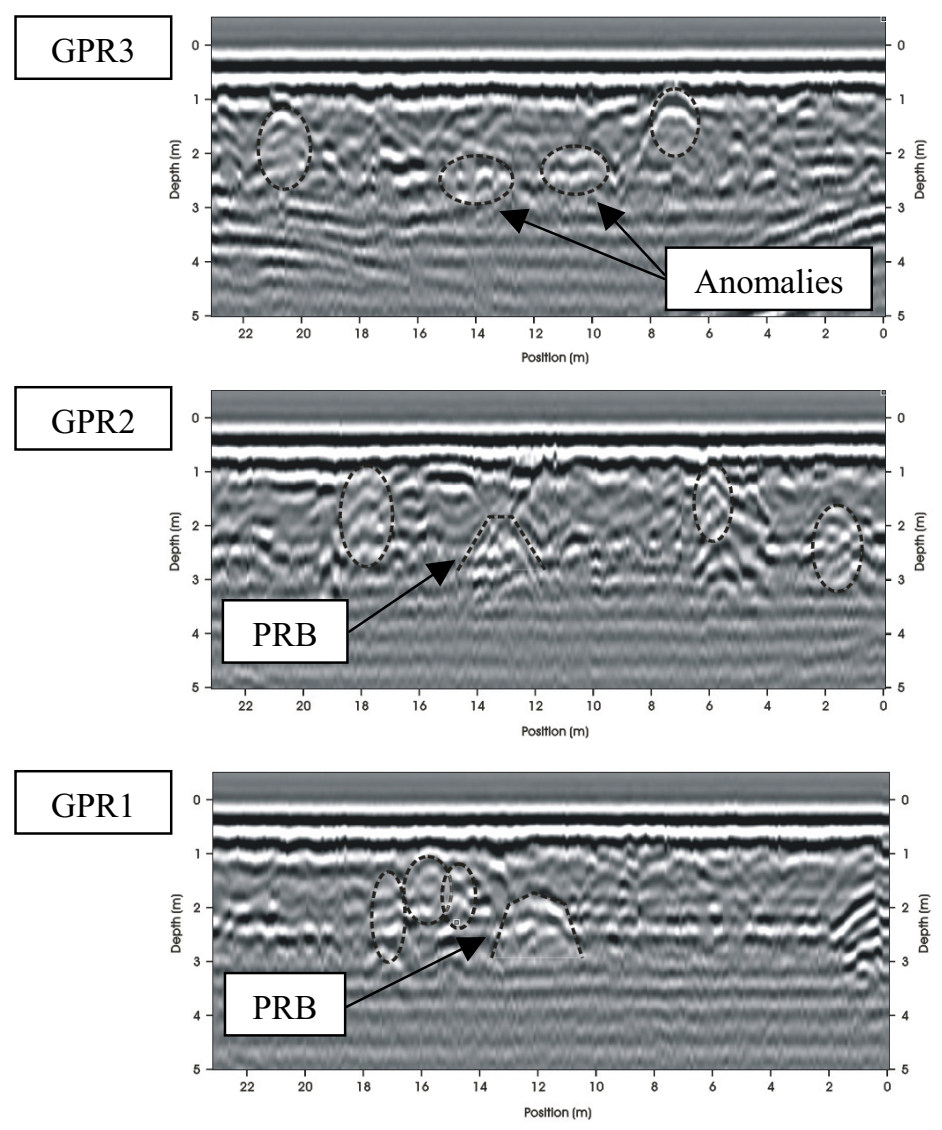

Figure 2: $\quad$ Radar images along grid lines GPR1-3, which are perpendicular to the direction of pile-type PRBs.

\subsection{Resistivity survey}

Results of the resistivity survey obtained from grid lines perpendicular to the pile-type PRBs are shown in figure 3 . Since reactive materials used for pile-type PRB construction had a narrow particle size distribution and large particle size (greater than $5 \mathrm{~mm}$ ), the electrical resistivity at the location of pile-type PRB was anticipated to be significantly lower than surrounding soils (especially densely compacted original soil). Greater porosity or volumetric water content of reactive materials brings about a decrease in electrical resistivity. Employing an electrode spacing of $1.5 \mathrm{~m}$, resolution of the resistivity image was expected to be sufficient to represent pile-type PRBs as low resistivity areas with widths of 2 to $4 \mathrm{~m}$. Considering that the pile-type PRBs were installed to depths reaching 7 to $8 \mathrm{~m}$ where the original soil was intact, its approximate location was found as indicated by the black dotted rectangles in figure 3 . The original soil was 
estimated to lie at a depth of 3 to $4.5 \mathrm{~m}$, under the assumption that it showed resistivity values greater than $84 \Omega \cdot \mathrm{m}$. Note that the estimated location of the pile-type PRBs based on 2-D resistivity images are in accord to that from interpretation of GPR images. In addition, buried steel pipe reacted to develop an area of low resistivity in grid line $\mathrm{R} 2$.

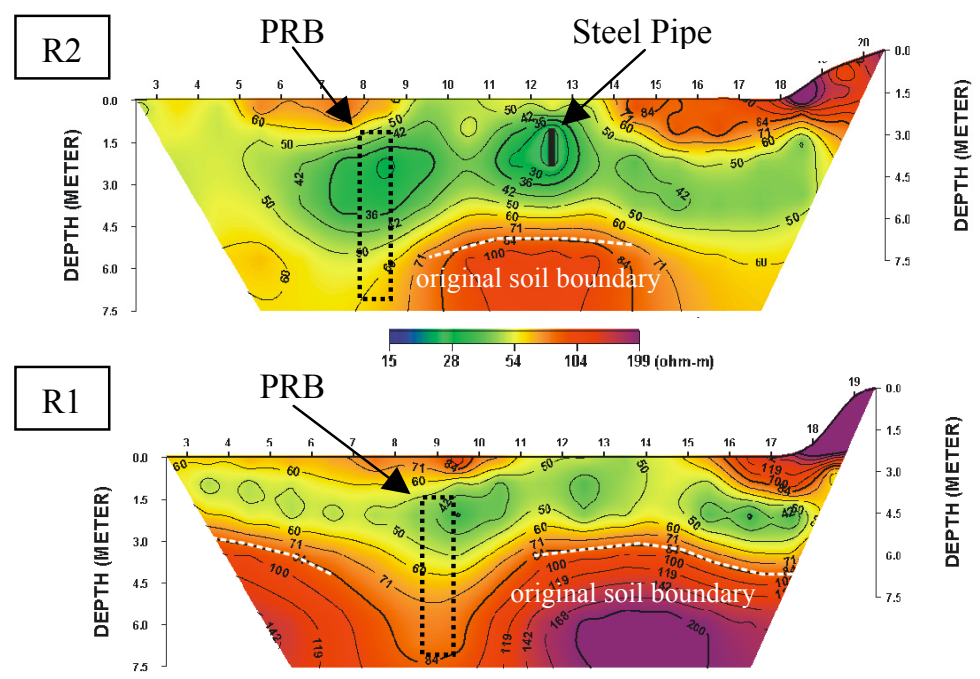

Figure 3: 2-D Resistivity images along grid lines R1 and R2 which are perpendicular to the direction of pile-type PRBs.

Assuming that the pile-type PRBs are located at the estimated locations shown in figure 3, no significant contrast in electrical resistivity was observed at the areas following its two opposite faces. Therefore, it was interpreted that either the contrast in resistivity was not sufficient enough to map any adsorption of heavy metals within the pile-type PRBs, or the pile-type PRBs are not experiencing any inflow of groundwater contaminated by heavy metals from the mine tailing dump. Laboratory analysis on groundwater samples is required for a clear verification. Based on the resistivity survey results, the pile-type PRB was found to be installed at adequate depths to intercept possible release of contaminants from the mine tailing dump.

Results of the resistivity survey obtained from grid lines parallel to the piletype PRBs are shown in figure 4. Similar to the results of figure 3, the reclaimed soil above original soil at the study site generally showed low resistivity values. High values of resistivity observed at depths above $1.5 \mathrm{~m}$ in gridline $\mathrm{R} 4$ can be attributed to the presence of the nearby mine tailing dump which is dominantly composed of large gravels and rocks.

Since bulk resistivity of soils can be estimated to be directly proportional to the porosity (which is volumetric water content at saturated state) and the electrical resistivity of the pore water based on the Archie's law [1], areas of low resistivity shown in image obtained from gridline R4 are believed to be areas that 
act as passageways for groundwater from the mine tailing dump. With resistivity values up to $21 \Omega \cdot \mathrm{m}$, these areas may contain various dissolved ions and possibly heavy metals released from the mine tailing dump. Therefore, they were selected as locations of high priority for groundwater and soil sampling to be performed.
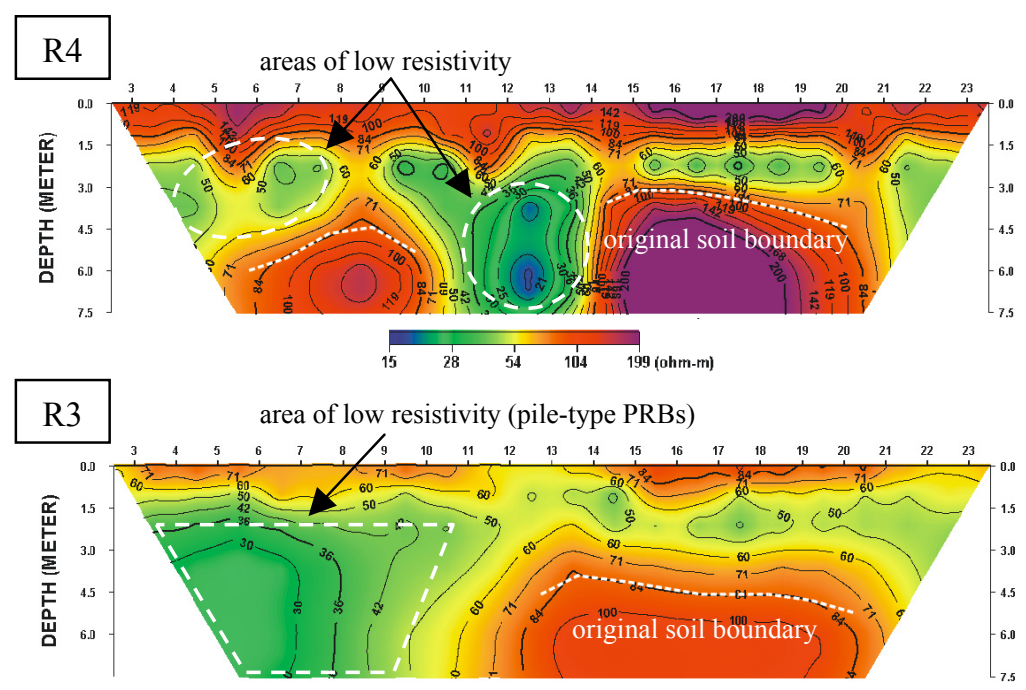

Figure 4: 2-D Resistivity images along grid lines R3 and R4 which are parallel to the direction of pile-type PRBs.

Area of low resistivity shown in image obtained from grid line R3 is believed to be a part of the pile-type PRBs installation. Although the gridline R3 was initially planned to be placed sufficiently away from the pile-type PRBs, the estimated location of the pile-type PRBs from GPR images and 2-D resistivity images R1 and R2 were found to be farther away than expected from the mine tailing dump. In addition, the estimated direction of the pile-type PRBs were not parallel with the mine tailing dump (refer to figure 5). As a result, grid line R3 is believed to partially overlap the location of pile-type PRBs. Another possible cause for the area of low resistivity may be inflow of surface water with higher electrical conductivity than water. A small stream runs perpendicular to the grid line R3, as shown in figure 1. Analysis on groundwater and surface water samples from the study site is required for a clear verification.

\section{Discussion}

Excavation to depths of 1 to $2 \mathrm{~m}$ were performed above anomalies observed in GPR images and regions of low resistivity observed in 2-D resistivity images, in order to verify the exact location of the pile-type PRBs. It was confirmed that the 
interpretation of the results of geophysical surveys were highly reliable. As shown in figure 5, the pile-type PRB was approximately 12 to $15 \mathrm{~m}$ away from, and not completely parallel to the slope of mine tailings dump. Use of geophysical surveys to locate PRBs employing non-conductive reactive materials is highly effective, since it can substitute or minimize site excavation (based on design plan), which is a destructive method and may cause costly damage. Figure 5 is a schematic diagram giving a summary of interpretations made based on geophysical surveys.

Interpretations of the 2-D resistivity images were successful in giving approximate locations of the original soil and reclaimed soil boundaries. Such geological information provides knowledge on possible spatial variations in the amount of groundwater flow nearby PRB installations. In addition, areas of low resistivity which can be interpreted as areas of high porosity (thus high water content at saturated state) or high concentration of dissolved ions can be selected as locations adequate for groundwater sampling. Such interpretations made from resistivity images become effective especially when the site subject to investigation lies over a large area.

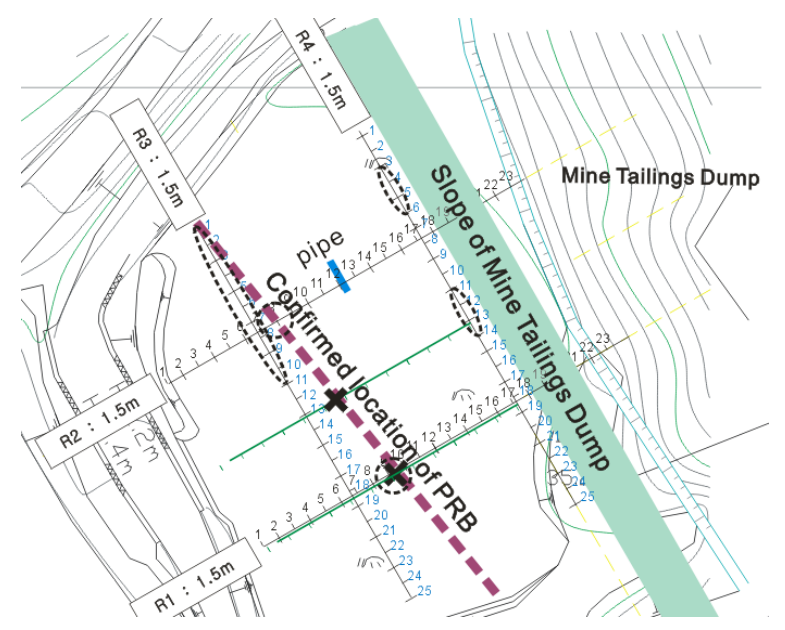

Figure 5: Schematic diagram showing the confirmed location of the PRBs from excavation. Dotted circles represent areas of low resistivity and black $x$ symbols indicate of anomalies in GPR images.

It was difficult to investigate possible migration of heavy metal contaminants in the groundwater by interpreting the 2-D resistivity images obtained perpendicular to the PRBs installation and comparing resistivity images obtained from front and back ends of the PRBs installation (for example, images shown in figure 4). The primary reason was due to soil excavation and reclamation conducted at the study site prior to pile-type PRBs installation which caused spatial variations in soil properties such as soil type and bulk density. In addition, the pile-type PRBs at the study site may not be experiencing sufficient inflow of conductive heavy metal contaminants. Assuming that there are no lithological 
variations, Benson and Turner [2] reported that at least a 5-10\% electrical contrast between contaminated and uncontaminated soil is required to successfully map a contaminant plume. However, it is suggested that repeating resistivity surveys over specific time intervals can be effective in investigating and monitoring the performance of PRB installations. By repeating surveys using on identical grid lines, comparison of resistivity images may be done quantitatively to give more promising results.

\section{Conclusion}

Geophysical surveys were performed on full scale pile-type PRB installation in order to investigate their applicability in providing information on the location of PRBs, nearby subsurface conditions including the movement of groundwater and qualitatively identifying the performance of PRBs. Main conclusions derived from the interpretation of the field study can be summarized as follows.

1) Use of geophysical survey to locate PRBs employing non-conductive reactive materials is highly effective, since it is a non-destructive method which can substitute or minimize site excavation based on the design plan.

2) Interpretations of the 2-D resistivity images were successful in giving approximate locations of the original soil and reclaimed soil boundaries. In addition, groundwater movement was estimated based by interpreting areas of low resistivity which may be viewed primarily as areas of high volumetric water content or areas that contain high total dissolved solids.

3) It was difficult to investigate possible migration of heavy metal contaminants in the groundwater by interpreting the 2-D resistivity images obtained perpendicular to the PRBs installation. However, it is suggested that repeating resistivity surveys over specific time intervals can be effective in investigating and monitoring the performance of PRB installations.

\section{References}

[1] Archie, G. E., The electrical resistivity log as an aid in determining some reservoir characteristics. Trans. AIME, 146, pp.54-62, 1942.

[2] Benson, R.C., Turner, M.S., Volgelsong, W.D. \& Turner P.P., Correlation between field geophysical measurements and laboratory water sample analysis. Proc. Surface and Borehole Geophysical Methods in Groundwater Investigations, pp. 178-197, 1985.

[3] Field Applications of In Situ Remediation Technologies: Permeable Reactive Barriers, U.S. Environmental Protection Agency, Office of Solid Waste and Emergency Response Technology Innovation Office, 2002.

[4] Hunaidi, O. \& Giamou, P., Ground-penetrating radar for detection of leaks in buried plastic water distribution pipes. Seventh International Conference on Ground Penetrating Radar, pp. 783-786, 1998. 
[5] Liang, L., Korte, N., Gu, B., Puls, R. \& Reeter, C., Geochemical and microbiological reactions affecting the long-term performance of in situ barriers. Advances in Environmental Research, 4, pp. 273-286, 2000.

[6] Wilkins, R. \& Puls R., Capstone report on the application, monitoring, and performance of permeable reactive barriers for ground-water remediation: Volume 1 - Performance evaluations at two sites, U.S. Environmental Protection Agency, Ground Water and Ecosystems Restoration Division, National Risk Management Research Laboratory, 2003. 